\title{
AS DATAS SIGNIFICATIVAS E O LUGAR DE MEMÓRIA NA FORMAÇÃO DOCENTE INICIAL - REFLEXÕES PERTINENTES
}

\author{
Rosimar Serena Siqueira Esquinsani \\ Universidade de Passo Fundo / UPF
}

\section{RESUMO}

O texto propõe reflexões sobre as datas significativas (comemorativas) a partir de três ênfases: como conteúdo da formação docente inicial; enquanto lugar de memória, e enquanto mecanismo para a constituição da identidade discente. Parte, para tanto, de uma pesquisa embasada na observação participante - e nos correlatos registros no diário de campo -, realizada ao longo de seis anos (2005-2010) na docência da disciplina de Fundamentos Metodológicos do Ensino de História para a educação infantil e anos iniciais de escolarização. Nesta direção, apresenta algumas dificuldades encontradas para o trato com o tema, com foco voltado para as questões metodológicas. Como conclusão, reitera as datas significativas como espaços de afirmação identitária, dignas de um olhar mais atento por parte de qualquer programa de formação docente inicial.

Palavras-chave: Datas Significativas. Lugar de Memória. Formação Inicial

\section{SIGNIFICANT DATES AND PLACE OF MEMORY IN INITIAL TEACHER TRAINING - RELEVANT CONSIDERATIONS}

\begin{abstract}
The text offers reflections on significant dates (commemorative) from three emphases: as the content of initial teacher training, as a place of memory, as well as a mechanism for the formation of student identity. Party for this purpose, a research based on participant observation - and the related records in the field diary - held over six years (2005-2010) in the teaching of Methodological Foundations of Teaching History for early childhood education and initial years of schooling. In this direction, it presents some difficulties to deal with the issue, with focus directed toward the methodological issues. In conclusion, we reiterate the significant dates as spaces of identity, worth a closer look by any program of initial teacher training.
\end{abstract}

Keywords: Significant Dates. Place of Memory. Initial Training.

Em virtude de minha formação inicial como licenciada em História, desde que iniciei a trajetória como docente no ensino superior - especificamente junto ao curso de Pedagogia -, tenho sido a responsável por disciplinas ligadas à área de história. Assim, tenho trabalhado ordinariamente com disciplinas afetas à metodologia do ensino de História, especificamente visando à formação para atuação do pedagogo junto à Educação Infantil e aos Anos Iniciais de escolarização.

Na Instituição de Ensino Superior onde atuo há, no currículo da Pedagogia, uma disciplina específica para o trato com a metodologia da história na fase inicial de escolarização. A referida disciplina já se chamou Metodologia da História e da Geografia dividida nos módulos I, II e III. Os primeiros dois módulos ou semestres com dois créditos (ou 30 horas-aula) cada. Já o módulo III tinha quatro créditos e totalizava 60 horas-aula. O módulo I era trabalhado no quinto semestre do curso, sendo sucedido pelo módulo II no 
sexto semestre e, por fim, o módulo III no sétimo semestre (penúltimo) do curso, apenas na habilitação para o trabalho com as Séries Iniciais de escolarização.

Após a reformulação curricular, fruto das Diretrizes Curriculares da Pedagogia (Resolução CNE/CP 1/2006, de maio de 2006), a disciplina passou a se chamar Fundamentos Metodológicos do Ensino de História, dividida em dois módulos ou semestres. O primeiro módulo com quatro créditos (60 horas) e o segundo com dois créditos (30 horas). Na organização curricular atual, o módulo I é trabalhado no quarto nível ou semestre do curso, enquanto o módulo II é trabalhado no nível cinco ou quinto semestre do curso. Em relação ao antigo esquema de oferta da disciplina, percebe-se a antecipação dos componentes para a metade do curso e a redução de carga horária.

Apesar da reformulação curricular e da concentração de ênfases na nova Pedagogia - Licenciatura Plena, a disciplina não perdeu sua essência e manteve, grosso modo, a proposta de contextualizar o ensino de História, abordando diferentes possibilidades metodológicas e perspectivas curriculares, bem como os principais conceitos afetos a História.

No bojo da docência com esta disciplina e da recorrência de certas observações inicialmente esporádicas, surgiu a necessidade da sistematização de achados. Tais dados foram, em um primeiro momento, confrontados e trabalhados como elementos de cunho exclusivo pedagógico e, por tal qualidade, parte da pesquisa entendida como atividade inerente à condição de docência, pois...

Fala-se hoje, com insistência, no professor pesquisador. No meu entender o que há de pesquisador no professor não é uma qualidade ou uma forma de ser ou de atuar que se acrescente à de ensinar. Faz parte da natureza da prática docente a indagação, a busca, a pesquisa. O que se precisa é que, em sua formação permanente, o professor se perceba e se assuma, porque professor, como pesquisador. (FREIRE, 2008, p. 32)

Porém, a reiteração dos achados tornou necessário o resguardo e o trabalho com os mesmos através da pesquisa acadêmica e do cotejamento desta com as referências bibliográficas atinentes aos achados.

Assim, pela recorrência do trabalho com a área e das observações realizadas, tenho percebido que há um certo senso comum que paira sobre alguns temas e abordagens de conteúdos da História (Diário de Campo). Esta percepção, refletida, me permitiu organizar e executar uma pesquisa qualitativa - caracteriza-se pelo procedimento da observação participante (MAY, 2004) através das aulas de metodologia da história -, sobre os temas que os discentes demonstram maior carência de dados e argumentos para o trabalho com os mesmos. Dentre estes temas, figuram aspectos acerca dos sentidos atribuídos aos episódios vulgarmente conhecidos como 'datas comemorativas' enquanto conteúdos atinentes à área (Diário de Campo).

A observação participante restou na produção de diários de campo contendo minhas percepções de pesquisadora acerca das aulas e da reação/recepção dos alunos diante de determinados temas, em especial, diante das datas comemorativas.

Todavia, a displicência em relação às datas comemorativas como tema inerente ao ensino de história não está explícita e expressa apenas nos alunos. Em razão da minguada produção científica envolvendo datas comemorativas (exemplarmente representado por MENEZES, 2009; VEIGA e GOUVEA, 2000; LEAL, 2006; SIROTA, 2005) e da ainda mais escassa produção abrangendo metodologias de transposição didática acerca do assunto (SILVA, 2002; AZEVEDO, 2010), é lícito crer que a própria academia não assume entre suas prioridades de pesquisa e produção do conhecimento, os pressupostos 
metodológicos pelos quais temas como datas comemorativas serão transpostos didaticamente para os alunos, em especial nos anos iniciais de escolarização.

\section{Descrevendo a pesquisa...}

A pesquisa informada na introdução deste artigo foi realizada ao longo de 12 semestres letivos - entre os anos de 2005 e 2010 -, com 19 turmas e 456 alunos. Em termos quantitativos, é possível indicar uma média de 24 alunos por turma, contudo houve oscilações (a menor turma teve 03 alunos, sendo que a lista de chamada da maior turma continha 42 discentes).

Todo o início de semestre era realizada uma sondagem inicial, onde os alunos expressavam seus conhecimentos prévios e expectativas em face do conteúdo previsto na ementa da disciplina. Por livre expressão dos discentes ou por intervenção da docente, o tema datas comemorativas era trazido à baila e, em torno do mesmo, levantavam-se expectativas e conhecimentos prévios.

Em momento oportuno ao longo do semestre - de acordo com o planejamento das aulas -, o assunto era desenvolvido através da exploração do mesmo pela técnica conhecida ordinariamente como 'explosão de ideias'. Tal técnica é organizada a partir da disposição de um tema no quadro (ou em lâmina, flip chart...) sendo que, através do diálogo, são arroladas palavras-chave afetas ao assunto e, a partir das mesmas, são realizadas associações. Grosso modo, se 'datas comemorativas' é o tema arrolado, os alunos vão apresentando palavras que remetam, em seu entendimento, ao tema em questão: calendário, horas cívicas; festas; desfiles; feriados, etc...

Em um segundo momento - com a intervenção da professora -, é elaborada uma rede de relações entre as palavras e o tema, momento em que são feitos agrupamentos entre palavras correlatas; identificação de sinônimos e 'limpeza' do campo conceitual.

Antes de outra intervenção docente os alunos são então, convidados a manifestarem-se sobre o que ensinariam em relação ao tema e como ensinariam (metodologicamente falando). Deste momento exploratório três aspectos tornaram-se motivo de preocupação: a) a visão estereotipada de história linear e factual; b) o desconhecimento do conceito e da associação do lugar de memória como elemento de construção identitária e, por fim, c) a análise superficial e a recorrência ao entendimento que datas comemorativas são momentos pontuais e isolados dentro de um currículo (Diário de Campo).

A maior parte dos alunos, inquiridos sobre como e em que momento trabalhariam o conteúdo 'datas comemorativas', inicialmente menosprezava a importância e o espaço do mesmo nos anos iniciais. Em seguida arrolavam uma série de datas no calendário, motivos de comemorações, horas cívicas, homenagens e desfiles, tratando tais datas como atividades compulsórias, sem ligação com algum planejamento de aula (Diário de Campo). Assim, poesias, hasteamento ou arreamento de bandeiras, teatros e entoação de hinos pátrios restavam como recursos pedagógicos meramente ilustrativos, sendo que uma mesma abordagem ou um mesmo recurso utilizado rasamente para tratar qualquer data comemorativa em um ano ou série poderia, sem sustos, ser utilizado igualmente em todos os demais anos ou séries, variando apenas as atividades (se entendidas como adequadas ou não àquela faixa etária).

Envoltas em uma grande expectativa, se acompanhadas de feriados; ou tratadas com certo desdém e muita superficialidade, as chamadas datas comemorativas eram vistas pelos alunos, como um estorvo, um atrapalho no desenvolvimento de seus planos de 
trabalho, além do que apenas as datas oficiais eram consideradas de relevância para justificar uma inserção no conteúdo (Diário de Campo).

Em face ao senso comum e à falta de indexação do tema com qualquer princípio epistemológico da história, tratei de realizar atividades sobre o tema em todas as turmas, visando desconstruir a leitura rasa sobre datas comemorativas e informando os pressupostos que conduziam e nutriam de sentido tais episódios para o ensino de história.

Para tanto foi, inicialmente, acordado que chamaríamos tais episódios de datas significativas e não mais de datas comemorativas, em razão da simplificação que este último termo adicionava a cada um dos episódios. Nem sempre as datas arroladas no calendário seriam de comemorações no sentido literal (exemplo clássico e óbvio: o dia 02 de novembro), todavia tais datas sempre seriam significativas a partir de um eixo condutor: os lugares de memória.

\section{As datas significativas e os lugares de memória...}

Diante das possibilidades metodológicas e curriculares para o tratamento das datas significativas e, paradoxalmente, diante da ideia recorrente de que as mesmas eram apenas um empecilho compulsório no desenho dos conteúdos ministrados - ideia amparada em grande medida, pela falta de interlocuções teóricas quantitativas e substanciais para abordagem do tema -, optei por associar datas significativas e lugares de memória.

Para tal tarefa, é fundamental o recurso ao já clássico texto de Pierre Nora a fim de demarcar o entendimento amplo do conceito de 'lugar de memória', que abrange:

[...] museus, arquivos, cemitérios e coleções, festas, aniversários, tratados, processos verbais, monumentos, santuários, associações [...]. Os lugares de memória nascem e vivem do sentimento que não há memória espontânea, que é preciso criar arquivos, que é preciso manter aniversários, organizar celebrações, pronunciar elogios fúnebres, notariar atas, porque essas operações não são naturais. (NORA, 1993, p. 13).

Nesta perspectiva, a memória precisa ser alimentada, nutrida, sustentada, pois o ato de lembrar não é tão óbvio quanto parece, sendo que a memória não é um dado natural, mas uma construção humana datada, razão pela qual "a memória se enraíza no concreto, no espaço, no gesto, na imagem, no objeto. A história só se liga a continuidades temporais, às evoluções, e às relações das coisas. A memória é o absoluto e a história o relativo." (NORA, 1993, p. 9).

Para sobreviver, a memória precisa de símbolos, ordenações, sequências e ritos. Dentre estes ritos, as datas significativas subjazem como estratégia capaz de organizar, sequenciar e alimentar memórias e consequentemente tecer identidades. Nesta perspectiva a memoria não é um dado natural, uma condição em si, mas o exercício de constante referência a um capital acumulado de situações, fatos, lugares, símbolos, etc... ao qual precisamos constantemente recorrer, pois "o que nós chamamos de memória, é de fato, a constituição gigantesca e vertiginosa do estoque material daquilo que nos é impossível lembrar, repertório insondável daquilo que poderíamos ter necessidade de lembrar." (NORA, 1993, p. 15).

Pierre Nora distingue, ainda, dois tipos de memória: uma memória tradicional (imediata) e uma memória transformada por sua passagem à condição de história. Para explicar esta passagem, o autor menciona o processo no qual, ao passo que a memória tradicional vai afastando-se furtivamente, “[...] nós nos sentimos obrigados a acumular religiosamente vestígios, testemunhos, documentos, imagens, discursos, sinais visíveis do 
que foi." (NORA, 1993, p. 15). No caminho de efetivação da memória transformada habitam, entre outros meios, as datas significativas como mecanismos do processo de constituição dos referenciais identitários de um dado grupo.

Aliás, cultuar a memória através de referenciais externos e coletivos, considerados enquanto patrimônio afetivo e identitário de um grupo, fez parte do processo de consolidação dos Estados Nacionais modernos, quando estes foram alçados a condição de "[...] fonte poderosa de significados para as identidades culturais modernas" (HALL, 2006, p. 49), costurando identidades a fim de acolher todos seus cidadãos na mesma "grande família nacional." (HALL, 2006, p. 59). Justamente naquele contexto, os lugares de memória assumiam o status de instrumento que cumpria inúmeras funções simbólicas, como cimentar a representação e o vínculo de pertencimento a uma determinada nação, impingindo legitimidade à mesma.

No período histórico posterior à consolidação dos Estados Nacionais, o sentido de preservação dos lugares de memória enquanto constituintes do patrimônio cultural de um povo permaneceu latente, agora com o sentido de união, de liga, de reverência, da lembrança constante de uma raiz identitária comum. A memória assume, desta sorte, um caráter coletivo: lembrar não é apenas recordar imagens e valores individuais, mas vinculálos a valores mais amplos e coletivos, que indicam o sentido de pertencimento do indivíduo que recorda.

Assim, é possível considerar que "as pessoas não são apenas cidadãos/ãs legais de uma nação; elas participam da idéia da nação tal como representada em sua cultura nacional" (HALL, 2006, p. 49) refletida, em grande medida, pelas datas significativas tanto as do calendário oficial, quanto (e, sobretudo) as datas expressas pelo calendário popular.

Isto porque a identidade é fortemente referenciada nos sistemas culturais. Deles ela depende e por eles é moldada.

\begin{abstract}
A identidade torna-se uma "celebração" móvel: formada e transformada continuamente em relação às formas pelas quais somos representados ou interpelados nos sistemas culturais que nos rodeiam [...] A identidade plenamente unificada, completa, segura e coerente é uma fantasia [...] à medida que os sistemas de significação e representação cultural se multiplicam, somos confrontados com a multiplicidade desconcertante e cambiante de identidades possíveis, com cada uma das quais poderíamos nos identificar - ao menos temporariamente. (HALL, 2006, p. 13).
\end{abstract}

Por outro lado, a identidade tem um aspecto de solidez, pois une o sujeito à estrutura, servindo de unidade e referência para o pertencimento, assim a "identidade [...] costura [...] o sujeito à estrutura. Estabiliza tanto os sujeitos quanto os mundos culturais que eles habitam, tornando ambos reciprocamente mais unificados e predizíveis." (HALL, 2006, p. 10). Ao se tornar palatável, a identidade também se torna tangível e, portanto, possível de ser proclamada, comemorada, narrada, festejada.

\title{
As datas significativas e a escola...
}

Em geral, as turmas partícipes da pesquisa, foram positiva e paradoxalmente receptivas as propostas da disciplina envolvendo as datas significativas (Diário de Campo). Tal receptividade, em grande medida, pode ser creditada ao "forte interesse popular pelas memórias históricas [...] uma reação à aceleração das mudanças sociais e culturais que ameaçam as identidades, ao separar o que somos daquilo que fomos" (BURKE, 2008, p.88). 
Tal interesse se constituiu em um terreno fértil para a transposição didática dos conteúdos de história a partir de propostas sócio-interacionistas (VYGOTSKY, 2005), tomando por premissa que o conhecimento se processa através de interações sociais e, no bojo deste processo, festejar/comemorar seriam mecanismos de interação envolvendo, sobretudo, o viés afetivo.

Para o trabalho com os alunos, as datas significativas foram descortinadas a partir de dois olhares: o olhar do grupo e o olhar do sujeito. O olhar do grupo materializa-se pela constituição do lugar de memória e o seu potencial de vivificar a identidade coletiva. Já o olhar do sujeito é particular e simbioticamente materializado pela experiência de si (LARROSA, 1994):

[...] a experiência de si não é senão o resultado de um complexo processo histórico de fabricação no qual se entrecruzam os discursos que definem a verdade do sujeito, as práticas que regulam seu comportamento e as formas de subjetividade nas quais se constitui sua própria interioridade. (LARROSA, 1994, p.43).

A experiência de si constitui-se a partir da identidade afetiva do indivíduo, o que não é um dado naturalizado e consensual, mas um constructo histórico e individual, largamente dependente das experiências pessoais do sujeito. Não é incomum, por exemplo, haver olhares díspares para uma mesma data significativa: há quem goste muito do Natal, há quem fique deprimido com a mesma data, pois...

A experiência de si, historicamente constituída, é aquilo a respeito do qual o sujeito se oferece seu próprio ser quando se observa, se decifra, se interpreta, se descreve, se julga, se narra, se domina [...]. E esse ser próprio sempre se produz com relação a certas problematizações e no interior de certas práticas. (LARROSA, 1994, p.43).

A experiência de si faz com que cada comemoração tenha um significado grupal e outro individual, sublinhando a premissa de que "a identidade muda de acordo com a forma como o sujeito é interpelado ou representado." (HALL, 2006, p. 21). Em outras palavras, a identidade precisa de constante alimentação, seja no sentimento de pertencimento ao grupo, seja nas experiências e significações individuais.

Para tornar o tema palatável utilizei-me, nas aulas de metodologia do ensino de história para educação infantil e anos iniciais de escolarização, de algumas técnicas e estratégias metodológicas que, de tão vilipendiadas, já ganharam o senso comum, mas que foram empregadas para ratificar as datas significativas pelos olhares coletivo e individual, como o uso de linhas do tempo pessoal, familiar e contextual e o cotejamento entre elas; pesquisas acerca das datas significativas na família e a importância e sentido das mesmas; resgate de tradições locais sobre datas significativas (como festejos comunitários); construção de painéis sobre episódios históricos e datas significativas, entre outras estratégias.

Grosso modo a maior dificuldade apresentada pelas turmas no trato com a questão desdobrava-se em dois pontos nevrálgicos: como ajustar-se a dinâmica das datas significativas, tendo em vista a profusão e quantidade das mesmas nos calendários; e como organizar o conteúdo de forma a contemplar expressivamente as datas significativas, sem trata-las de forma superficial e tampouco, para abordá-las, abrir mão de uma lógica de organização dos conteúdos. 
Em razão do primeiro desdobramento da questão foi consensual a compreensão, após algumas discussões (Diário de Campo), que nenhuma data significativa cumpriria seu papel de lugar de memória (NORA, 1993) se fosse retirada do contexto de produção. Assim uma data significativa não tem, para a metodologia do ensino de história na educação infantil e anos iniciais de escolarização, um valor intrínseco. Qualquer data, para adquirir relevância e sentido, necessariamente faz parte de uma teia de relações com outras datas mensuráveis, que fornecem uma lógica processual e contextual a mesma.

Por esta perspectiva, não faz o menor sentido o estudo de determinadas datas em determinados anos ou séries de escolarização. Tampouco, há a necessidade do recurso/aprisionamento constante ao calendário. As datas subjazem naturalmente do planejamento do professor, sendo vinculadas (e assim escolhidas) de acordo com as perspectivas da turma e os acontecimentos conjunturais.

Não faz sentido lembrar compulsoriamente de episódios como Olimpíadas em anos ímpares, por exemplo. Ou 'comemorar' a Queda da Bastilha em uma turma de primeiro ano do ensino fundamental. Ou ainda organizar uma passeata para marcar uma data significativa desconhecida ou pouco apreciada na comunidade. Se o calendário for tomado como orientador, todo dia há uma data significativa mensurada, todavia nem sempre tal data é, de fato, relevante para a construção identitária do aluno.

Quanto ao segundo desdobramento, ou a relativa dificuldade em organizar o conteúdo de forma a contemplar expressivamente as datas significativas percebemos, após alguns debates nas turmas, que havia dois riscos a serem observados. De um lado a possibilidade de - para a inclusão e trato do tema datas significativas no rol de conteúdos de uma dada etapa, ano ou série de escolarização inicial -, haver a compulsão por um tratamento raso e superficial, que considerasse apenas a inserção das datas como argumentos ilustrativos de outro assunto curricular, por exemplo. De outro lado, havia o risco de tratar das datas significativas sem uma lógica de organização dos conteúdos, soltas e dispersas como apêndices em relação a outros temas.

Diante desta dupla problemática que não é, de forma alguma, menor no trato com a metodologia da educação infantil e anos iniciais de escolarização, foi necessário um exaustivo trabalho sobre as diferentes possibilidades de organização curricular que atendessem a um duplo desafio: considerassem o sócio-interacionismo como premissa teórica básica e agregassem o tema datas significativas sem incorrer na superficialidade. Cheguei, tanto pelas discussões no colegiado do curso, quanto pelas minhas pesquisas em relação ao assunto, ao indicativo do tema gerador (FREIRE, 2003, 2008, 2008b) como princípio de organização curricular capaz de atender a este duplo desafio.

Os temas geradores são fortemente inspirados nos Complexos Temáticos de Conhecimento propostos pelo educador soviético Mousei Mikhaylovich Pistrak (18881940) que, a serviço da Revolução Russa no primeiro quartel do século XX, propunha a transformação da escola burguesa através da composição de unidades didáticas de ensino por complexos temáticos. Por esta perspectiva, a organização do trabalho escolar e dos conteúdos de ensino, “... deve ter significado relevante no âmbito social, de modo que permita ao aluno a compreensão do real e que depois possa ser associado sucessivamente aos temas de outros complexos." (PISTRAK, 2002, p. 18).

O critério para seleção dos temas do complexo é garimpado no plano social, de modo que permita ao discente a compreensão aproximada da realidade. Trata-se de definir um tema fundamental que possua um valor real e possa agrupar ao seu redor os demais temas relevantes, com vistas a análise da realidade, pois: 
O trabalho na escola, enquanto base da educação, deve estar ligado ao trabalho social, à produção real, a uma atividade concreta socialmente útil, sem o que perderia seu valor essencial, seu aspecto social, reduzindo-se, de um lado, à aquisição de algumas normas técnicas e, de outro, a procedimentos metodológicos capazes de ilustrar este ou aquele detalhe de um curso sistemático. (PISTRAK, 2002, p. 38)

Por seu tempo Paulo Reglus Neves Freire (1921 - 1997), apostando também na realidade e no contexto como elemento desencadeador da estruturação dos conteúdos (e outras relações), aponta o Tema Gerador como eixo articulador da organização do trabalho escolar. Nesta perspectiva, o tema gerador é entendido como o assunto que centraliza o processo de ensino-aprendizagem, sobre o qual acontecem os estudos, pesquisas, análises, reflexões, discussões e conclusões. (FREIRE, 2008). O processo de escolha desses assuntos, problemas ou temas geradores é fruto de uma mediação entre as responsabilidades dos professores e os interesses dos alunos.

O elenco dos temas (que serão) geradores começa, pois, por uma situação do presente, da existência concreta dos sujeitos envolvidos no processo educativo, sendo que é a partir desta situação que se principia a organização do "conteúdo" didático. Escolher os temas geradores é buscá-los/recrutá-los na vida e na realidade, para posteriormente transformá-los em conteúdos/assuntos da ação educativa. De acordo com Paulo Freire: "Não se trata de ter nos homens o objeto da investigação [...], mas o seu pensamentolinguagem referido à realidade, os níveis de sua percepção desta realidade, a sua visão do mundo, em que se encontram envolvidos seus 'temas geradores". (FREIRE, 2008b, p. 88).

Tomados como proposta de organização curricular, os temas geradores permitem uma organização contextual dos temas de estudo, liberando-os de qualquer elenco rígido de conteúdos e de uma sequencia inflexível para o trato com os mesmos.

Todavia tenho aqui novamente um paradoxo: o trabalho com as datas significativas só fará sentido na escola se as referidas datas forem contextualizadas e inseridas na construção identitária (seja individual ou coletiva) do discente. Por outro lado, afirmo que a organização curricular que me parece mais adequada para inserção orgânica das datas significativas no rol de conteúdos da escola é a que passa pelos temas geradores. Entretanto, sem sentido para os alunos, tais datas jamais serão elencadas por eles como possíveis (e significativos) temas geradores!

Isto porque o problema não se coloca unicamente na esfera da organização curricular mas, e antes, na esfera do tratamento metodológico que o professor dará a temática. Provida de sentido social uma data significativa constituirá um lugar de memória e fará parte das injunções de sentido discente. Porém, seja qual for a fórmula adotada para a organização curricular de uma escola, se as datas significativas não forem nutridas de sentido para a prática pedagógica, elas não passarão de meras atividades compulsórias e arbitrárias. Trata-se de uma decisão mais metodológica do que curricular.

Assim se as datas significativas - quando tratadas como lugares de memória -, são mecanismos para a afirmação identitária coletiva e também para a experiência de si, é lícito supor que tais datas receberão sentido por parte dos alunos na proporção exata em que forem capazes de cumprir a função de alimento da memória.

Há, pois, uma chance considerável para as datas significativas sobreviverem no contexto escolar sem serem massificadas e tratadas fria e compulsoriamente de um lado; ou, por outro lado, serem alocadas de maneira artificial nos conteúdos já definidos para o trabalho pedagógico. Se consideradas como mecanismos ou instrumentos de construção da identidade e da experiência de si, tais datas passarão a ser dotadas de aura simbólica 
(NORA, 1993), com o condão de corroborar para a legitimação da escola como lugar de identidade e, igualmente, enquanto instituição moderna.

É necessário zelar pelos lugares de memória. Eles impedem que o esquecimento justaponha nossas lembranças e embaralhe nossas ameaçadas percepções e identidades, pois se "o que eles defendem não estivesse ameaçado, não se teria, tampouco, a necessidade de constituí-los. Se vivêssemos verdadeiramente as lembranças que elas envolvem, eles seriam inúteis (NORA, 1993, p.13). Os lugares de memoria e seus mecanismos precisam constituir-se, por esta lógica e por sua natureza e condição, objetos do ensino nas escolas.

\section{Conclusões provisórias}

A pesquisa é uma condição inerente a docência. Não há razão para dicotomizar tais atividades. Se ensino, compreendo que devo também pesquisar. Pesquisar a reação dos alunos diante de um acontecimento, suas angustias, a recepção acerca de um tema, suas dúvidas em relação a um conteúdo, etc.

Não há ensino sem pesquisa e pesquisa sem ensino. Esses que-fazeres se encontram um no corpo do outro. Enquanto ensino, continuo buscando, reprocurando. Ensino porque busco, porque indaguei, porque indago e me indago. Pesquiso para constatar e constatando, intervenho, intervindo educo e me educo. Pesquiso para conhecer o que ainda não conheço e comunicar ou anunciar a novidade. (FREIRE, 2008, p.32)

Deste modo, não pude deixar de perceber a angústia dos alunos diante de certos assuntos, como o tema em foco: datas significativas. Uma angústia que parecia indicar que aquele conteúdo estava desprovido de função social ou relevância. Movidos por um espírito em grande medida pragmatista, os alunos elaboravam reações de negação diante do que não produzia sentido em seu percurso de formação inicial, sobretudo na formação inicial em nível superior.

De certa maneira, os alunos reproduziam o descaso com o qual o tema tinha sido tratado ao longo de suas vidas escolares: pintar desenhos; recortar bandeiras; participar de horas cívicas; declamar poemas, vender rifas para marcar aniversários de instituições; participar de competições; decorar a letra de músicas; usar roupas e/ou acessórios descontextualizados para comemorar algum dia especial; pintar o rosto; empunhar adereços; aprender contos e causos que remetiam a culturas distintas e distantes da sua, entre outras inúmeras atividades (Diário de Campo) que repetiam-se ao longo dos anos, variando apenas o desenho mimeografado ou a canção a ser entoada.

Provido deste referencial de memória, o ensino das datas significativas tem se feito acompanhar - na interpretação dos discentes partícipes da pesquisa -, por uma desconfiança em relação ao potencial pedagógico de tais datas (Diário de Campo). Os alunos, via de regra, não percebem tais datas como fontes de conteúdo escolar, tampouco com fôlego epistemológico suficiente para merecer, da parte dos mesmos, um esforço maior do que uma abordagem rasa e pontual.

Em geral as comemorações encetadas no âmbito escolar e suscitadas por datas significativas não têm superado o proselitismo ou a repetição, relegando o potencial pedagógico de tais eventos a uma sequencia de atividades mais ou menos previsíveis e a vinculação dos mesmos a estratégias de marketing para a venda de produtos e/ou serviços.

A organização de um currículo que centralize as datas significativas, terá, ao meu ver, pouco impacto no redimensionamento da questão e no trato adequado ao tema. Desta forma, a questão se coloca muito mais como uma decisão metodológica do que curricular. 
Se tratada adequadamente, uma data significativa poderá ocupar um espaço importante e central nas práticas pedagógicas voltadas para o ensino de história na educação infantil e anos iniciais de escolarização. No entanto, se desprovida de sentido, qualquer data significativa, por mais relevante que possa parecer, não deixará de sentir o gosto amargo do desdém por parte dos alunos, pois será arbitrária e desvinculada com os necessários elos de memória.

Comemorar é mais do que lembrar. É significar, prover de sentido, de sentimento. Justo por esta razão as datas significativas ocupam a listagem dos lugares de memória. Tais datas contém um potencial de memória e referência identitária que não pode ser menosprezado, sobretudo quando tratamos da formação inicial do pedagogo.

Nesta direção, é mister direcionar um trato mais cuidadoso para a questão: por mais que possamos considerar as datas significativas como parte das "tradições inventadas que ligam passado e presente" (HALL, 2006, p.72), as mesmas consubstanciam-se em espaços de afirmação identitária, seja coletiva ou individualmente, sendo merecedoras de um olhar atento por parte de qualquer programa de formação docente inicial.

\section{Referências}

AZEVEDO, Patrícia Bastos de. O desafio do ensino de história nas séries iniciais e a questão do nacionalismo. Atos de Pesquisa em Educação. Blumenau: FURB, vol. 5, n. 3, p. 338-355, 2010.

BURKE, Peter. O que é história cultural? Tadução de Sérgio Goes de Paula. 2. ed. Rio de Janeiro: J. Zahar, 2008. 215 p.

FREIRE, Paulo. Pedagogia da Esperança: um reencontro com a Pedagogia do Oprimido. $11^{a}$ ed. Rio de Janeiro: Paz e Terra, 2003. 245 p.

Pedagogia da autonomia: saberes necessários à prática educativa. 37. ed. São Paulo: Paz e Terra, 2008. 148 p.

Pedagogia do oprimido. 47. ed. Rio de Janeiro: Paz e Terra, 2008b. 213 p.

HALL, Stuart. A identidade cultural na pós-modernidade. Tradução de Tomaz Tadeu da Silva e Guacira Lopes Louro. 11. ed. Rio de Janeiro: DP\&A, 2006, 102p.

LARROSA, Jorge. Tecnologias do Eu e educação. In: SILVA, Tomaz Tadeu da. (Org.) $\mathbf{O}$ sujeito da educação: estudos foucaultianos. Petrópolis: Vozes, 1994, pp. 35-87.

LEAL, Elisabete da Costa. O calendário republicano e a festa cívica do descobrimento do Brasil em 1890: versões de história e militância positivista. História. Franca: UNESP, vol. 25, n. 2, p. 64-93, 2006.

MAY, Tim; CORTES, Soraya Maria Vargas (Rev.) Pesquisa social: questões, métodos e processos. Tradução de Carlos Alberto Silveira Netto Soares. 3. ed. Porto Alegre: ARTMED, 2004. 288 p.

MENEZES, Renata de Castro. Celebrando São Besso ou o que Robert Hertz e a Escola Francesa de Sociologia têm a nos dizer sobre festas, rituais e simbolismo. Religião e Sociedade. Rio de Janeiro: Instituto de Estudos da Religião, vol. 29, n. 1, p. 179-199, 2009.

NORA, Pierre. Entre memória e história: a problemática dos lugares. Revista Projeto História. São Paulo: PUC, vol. 10, p. 07-28, 1993. 
PISTRAK, Mousei Mikhaylovich. Fundamentos da escola do trabalho. Tradução de Daniel Aarão Reis Filho. 2. ed. São Paulo: Expressão Popular, 2002. 224p.

SILVA, Helenice Rodrigues da. Rememoração/comemoração: as utilizações sociais da memória. Revista Brasileira de História. São Paulo: Associação Nacional de História ANPUH, vol. 22, n. 44, p. 425-438, 2002.

SIROTA, Régine. Primeiro os amigos: os aniversários da infância, dar e receber. Educação e Sociedade. Campinas: Unicamp, vol. 26, n. 91, p. 535-562, 2005.

VEIGA, Cynthia Greive; GOUVEA, Maria Cristina Soares. Comemorar a infância, celebrar qual criança? Festejos comemorativos nas primeiras décadas republicanas. Educação e Pesquisa. São Paulo: USP, vol. 26, n. 1, p.135-160, 2000.

VIGOTSKY, Lev. S. Pensamento e linguagem. Tradução de Jefferson Luis Camargo. 3. ed. São Paulo: Martins Fontes, 2005. 194 p.

\section{Fontes documentais:}

Diários de campo produzidos entre março de 2005 e dezembro de 2010

Recebido em: $\quad$ 07/08/11

Aprovado em: $27 / 08 / 11$ 